Archives

6 | 1990

Varia

\title{
La forêt dans la culture chinoise
}

\section{Michel Cartier}

\section{OpenEdition \\ Journals}

\section{Édition électronique}

URL : http://journals.openedition.org/ccrh/2865

DOI : $10.4000 /$ ccrh.2865

ISSN : 1760-7906

\section{Éditeur}

Centre de recherches historiques - EHESS

\section{Édition imprimée}

Date de publication : 15 octobre 1990

ISSN : 0990-9141

\section{Référence électronique}

Michel Cartier, "La forêt dans la culture chinoise », Les Cahiers du Centre de Recherches Historiques [En ligne], 6 | 1990, mis en ligne le 20 mars 2009, consulté le 22 avril 2019. URL : http:// journals.openedition.org/ccrh/2865; DOI : 10.4000/ccrh.2865

Ce document a été généré automatiquement le 22 avril 2019

Article L.111-1 du Code de la propriété intellectuelle. 


\title{
La forêt dans la culture chinoise
}

\author{
Michel Cartier
}

1 La Chine contemporaine compte parmi les pays disposant de très peu de réserves forestières et certains experts envisagent même la disparition totale à moyen terme des forêts si des mesures de protection ne sont pas prises rapidement. Cette situation est-elle un legs du passé ou provient-elle d'une inattention particulière à l'environnement aggravée par la récente croissance démographique? On discute beaucoup à propos de l'extension effective de la forêt chinoise dans l'Antiquité. Bien que la Chine soit présentée, en ce qui concerne la couverture végétale, comme un espace unique où l'on passe par une série d'insensibles transitions, de la forêt tropicale à la taïga sibérienne, des études sur les pollens fossiles semblent exclure la possibilité d'une couverture forestière continue. Les massifs forestiers du Sud auraient fait place à mesure que l'on montait vers le Nord, à une steppe arborée puis à des forêts de feuillus. Les préhistoriens ont d'ailleurs pris l'habitude d'opposer les cultures forestières méridionales, au sein desquelles auraient eu lieu la domestication du riz, à des cultures nordiques de steppes, caractérisées par la culture du millet. La faune ancienne dont on retrouve les vestiges dans la Grande plaine, et que les artistes de l'Antiquité aiment à représenter, correspond assez bien à une faune de savane: des félins tels que tigres et panthères, de grands herbivores, en particulier des cervidés, des éléphants et des rhinocéros. La chasse aurait joué un rôle important dans les genres de vie de l'époque. Il n'en demeure pas moins que la mise en valeur liée à la culture des céréales, s'accompagne de défrichements et qu'elle entraîne dès lors un recul sensible de la forêt et du gros gibier. On oppose volontiers l'impact, sur un environnement plus limité, des habitants du Sud qui cultivent des clairières et laissent se reconstituer la couverture végétale, à l'influence négative exercée par leurs compatriotes du Nord, qui pratiqueraient une sorte d'agriculture itinérante avec des périodes de jachères, cette représentation de l'Antiquité chinoise reste néanmoins conjecturale.

2 Quel que soit le degré de vérité du tableau que l'on vient d'esquisser, il n'en demeure pas moins que les Chinois de la fin de la période pré-impériale ( $\mathrm{V}^{\mathrm{e}}-\mathrm{III}{ }^{\mathrm{e}}$ siècles av. J.C.) ont - plus spécialement dans la partie orientale de la Grande plaine (abords du Shandong) - 
déjà conscience d'une crise écologique aiguë. Le philosophe Mencius, le premier, déplore la « calvitie des montagnes " privées de leur couverture végétale. Si, plus près de nous, le philosophe confucéen Xunzi exprime sa confiance dans la capacité de "régénération spontanée " de la nature - zi-ran, terme qui peut précisément être rendu par « spontanéité »- ses contemporains les précurseurs de la pensée économique que sont les « légistes " préconisent au contraire une "nationalisation » des forêts et des marécages avec, suivant les cas, alternative d'ouverture ou de fermeture selon la saison, ou interdiction pure et simple d'accès au commun des mortels. Cette politique traduirait tout ensemble une volonté délibérée de réserver aux souverains les ressources précieuses pouvant être extraites des massifs montagneux et des étendues d'eau, en particulier les métaux des mines et le sel des lacs d'eau salée, tout en ménageant des combustibles et des bois d'oeuvre en train de devenir rares. Il est essentiel de noter à propos du bois d'oeuvre l'importance accordée au bois dans une architecture qui n'utilise que des structures porteuses en bois et assimile en conséquence les architectes à des charpentiers (mythe de Lu Ban).

3 Nous connaissons très mal l'histoire des forêts chinoises. Au cours des siècles qui suivent l'unification impériale, le courant naturaliste associé au taoïsme met volontiers l'accent sur le caractère de refuge des montagnes encore boisées du Sud, qui sont supposées être le domaine des «immortels». Les premiers textes du taoïsme religieux opposent directement les "mangeurs de grains", les loyaux sujets du pouvoir politique, aux ermites vivant, à la manière des sauvages, des produits de la cueillette (baies, champignons, racines sauvages). Les forêts sont des lieux de retraite; elles sont tout naturellement associées au mouvement monastique, aussi bien taoïste que bouddhique, qui, à la différence de ce qui se passe dans l'Occident médiéval, ne se consacre nullement à leur mise en valeur et à des défrichements.

4 La forêt apparaît tout au plus comme un réservoir de matières rares, à la fois d'origine animale et végétale, et plus spécialement comme le lieu de la collecte des médicaments et des drogues naturelles. Ses habitants, beaucoup moins nombreux que les agriculteurs des plaines et des vallées, sont d'ailleurs taxés en produits de chasse et de cueillette.

Une thèse célèbre, développée avec succès voici une vingtaine d'années, par l'historien américain Robert Hartwell, liait paradoxalement les progrès de l'économie Song ( $\mathrm{x}^{\mathrm{e}}$-XIII ${ }^{\mathrm{e}}$ siècles) à une nouvelle crise du bois. C'est pour pallier la rareté grandissante du bois servant à la préparation du charbon de bois que les métallurgistes se seraient tournés vers le charbon fossile. Il n'est pas douteux que l'augmentation de la population, jointe aux progrès des arts du feu (métallurgie, sidérurgie, céramiques, porcelaines), accroît les besoins en bois et, partant, entraîne des déforestations. Il est en revanche beaucoup plus difficile de reconstituer les étapes de cette crise. Des mesures effectuées en aval d'Yichang, dans la région où le Yangzi quitte les fameuses gorges qui permettent les communications entre les hautes vallées du Sichuan et le bassin du Hubei, mettent en évidence une accélération de la sédimentation à partir précisément des Song. Depuis le XII e siècle, le cône de déjection formé dans cette zone s'exhausse environ d'un mètre par siècle, et non plus de quelques décimètres, phénomène que les géologues lient à une augmentation du ruissellement superficiel consécutive à la disparition de la couverture végétale des montagnes situées en amont. Des travaux sur l'histoire du climat font également apparaître une recrudescence des inondations, liées elles aussi à la déforestation, dans diverses régions de Chine à des dates échelonnées entre le $\mathrm{XVI}^{\mathrm{e}}$ et le $\mathrm{xVIII}^{\mathrm{e}}$ siècle. Cette dégradation de la forêt doit évidemment être mise en relation avec la 
croissance démographique - la population franchit la barre des cent millions sous les Song pour atteindre 400 millions dans la première moitié du XIX ${ }^{e}$ siècle - et la nécessité de défricher de nouvelles terres.

La déforestation est-elle principalement le résultat de la croissance démographique, comme semblent le penser la plupart des auteurs modernes, ou tient-elle également à des facteurs culturels ? Li Bozhong, un historien plus particulièrement préoccupé d'écologie, qui vient de consacrer une série d'études à la région du Jiangnan, entre Nankin et Shangaï, y diagnostique une crise du bois remontant au xvIII ${ }^{\mathrm{e}}$ siècle, qu'il met en rapport précisément avec l'évolution démographico-économique de la Chine du Sud. En tout état de cause, le pourtour du lac Taihu ne dispose alors plus, depuis fort longtemps, de réserves forestières. Le bois, et plus spécialement le bois d'œuvre y serait devenu beaucoup plus rare. Une enquête sur l'histoire de l'architecture menée récemment dans la région en question par une équipe dont nous faisons partie, n'a pourtant pas permis de déceler de modification importante des techniques de construction avant le début du $\mathrm{xx}^{\mathrm{e}}$ siècle ; tout au plus révèle-t-on une substitution du pin américain, importé par le port de Shangaï, au bois d'oeuvre du Sud-est acheminé par flottage, en descendant les rivières, puis par trains de bois sur le Grand Canal. Cette substitution s'expliquerait plus par des facilités de transport que par un épuisement des réserves indigènes. De fait, plusieurs grands massifs forestiers subsistent et sont exploités jusqu'au milieu du $\mathrm{xx}^{\mathrm{e}}$ siècle, aussi bien le massif montagneux des Huangshan que les montagnes du Fujian, qui continuent à approvisionner la région. Or, il n'est pas sans intérêt de noter que ces zones, à la différence $\mathrm{du}$ Nord où les forêts ne font pas l'objet d'une appropriation mais appartiennent théoriquement à l'Etat, ont privatisé leurs forêts depuis au moins quatre ou cinq siècles, et dans certains cas dès la dynastie des Song, ainsi que l'atteste la transmission jusqu'à nous de titres de propriété et de contrats de plantation et d'exploitation. Il est donc tentant de considérer la conservation de massifs forestiers, au moins dans les régions où les conditions climatiques permettent la reconstitution de la couverture végétale, comme le résultat d'une gestion plus soigneuse qui allait jusqu'à interdire, par exemple, l'accès des plantations pendant la période de reprise des arbres ; la déforestation apparaitrait jusqu'à un certain point comme la conséquence d'un manque de vigilance. Un contre-exemple peut être en effet fourni par la dégradation rapide des couvertures forestières de ces régions épargnées à l'époque plus récente de la collectivisation et des communes populaires, lorsque les forêts font retour au domaine public, avec tout ce que cette notion implique d'indifférence à l'environnement.

\section{AUTEUR}

\section{MICHEL CARTIER}

Michel CARTIER est directeur d'études au Centre d'Études Comparatives du Monde Chinois (EHESS). 